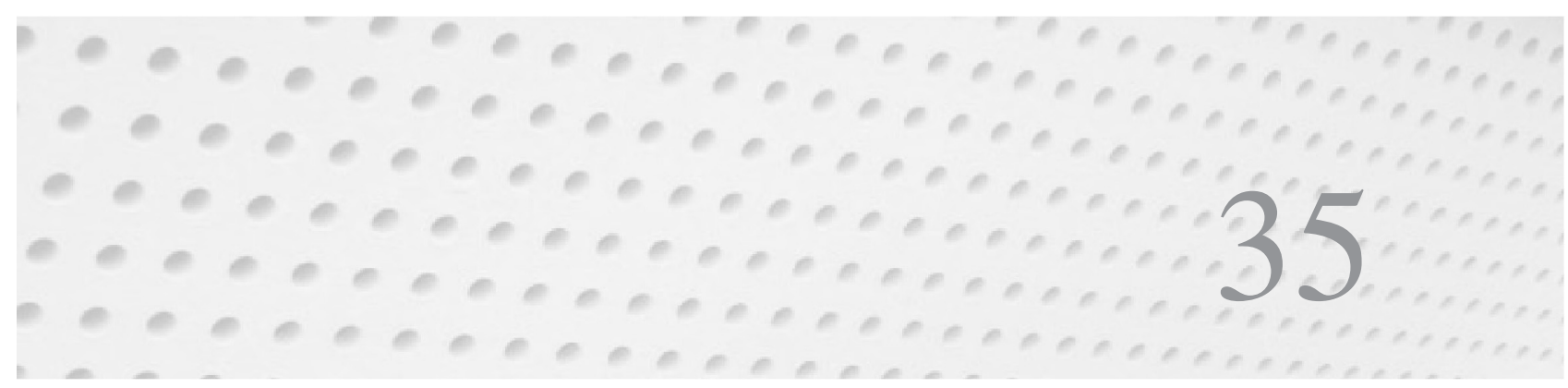

\title{
Sustainable Development and Governance
}

\author{
Yvonne Rydin
}

\section{INTRODUCTION}

The term 'sustainable development' is part of the common currency of public policy nowadays. International organizations, those at the level of the nation-state and the locality, within the private and public sectors all claim sustainable development as an objective. The adjective 'sustainable' has become so widely used in policy and marketing literature as to become almost meaningless. Indeed some consider that the parent term 'sustainable development' has lost any sense of coherent meaning through the multiple demands made of it. It is criticized for the inherent ambiguity that allows for so many different situations and possible futures to be described as contributing to 'sustainable development'. It is tempting to relegate the term to a conceptual rubbish bin as having no integrity or useful conceptual 'bite', rather in the way that the 'public interest' has been disposed of. However, to do so would be to dismiss the efforts that historically and currently lie behind the development and use of the concept to achieve advances in terms of social justice and environmental protection.

In this chapter, the history of the concept of sustainable development is briefly outlined, before discussing key dimensions of the concept itself, and drawing out the implications of different definitions. Then the relationship of the sustainable development agenda to contemporary patterns of governance is explored, defining more precisely what 'governance' means and explaining its particular significance to the sustainable development agenda. Finally, the way that governance processes can actually contribute to achieving sustainable development is examined, with particular reference to the local and community level.

\section{THE RISE OF THE SUSTAINABLE DEVELOPMENT AGENDA}

Most histories of the concept attribute its earliest uses to the International Union for the Conservation of Nature (IUCN, 1980). However, its contemporary relevance can be traced back to the United Nations' World Commission on Environment and Development, set up in 1984 and chaired by Gro Harlem Brundtland, then Prime Minister of Norway and since head of the World Health Organization. This Commission had its roots in two different strands of United Nations (UN) activity. On the one hand, it was conceived of as the successor to the commission chaired by Willie Brandt, ex-Chancellor of West Germany, which resulted in the North-South report (ICIDI, 1980) calling for a renegotiation of the relationship between more and less developed countries. Hence the emphasis on development within its terms of reference was a signal that global patterns of economic inequality were to be a key focus. In the context of the 1980s - before the end of the Cold War and the physical collapse of the Berlin Wall - relationships between nation-states were also framed in terms of conflict and, in particular, the threat of nuclear conflict.

On the other hand, the Commission was also taking forward the UN's work on environmental issues and, indeed, reshaping this work. Previously the 
UN had seen environmental issues largely in terms of how the physical environment affected human needs through the adequacy of housing, water provision and food security. Key issues were loss of soil fertility and water management. These were highlighted at the UN Habitat Conference held in 1972 in Stockholm. By the 1980s the environmental agenda had broadened out from this local and strictly anthropocentric focus. The background to this was the emergence of a scientific consensus on key aspects of global environmental change. This threw the emphasis on how global environmental systems operated and how individual, spatially fixed activities could - in aggregate - significantly alter these global systems, in turn impacting on people across the world.

Although not discussed in any depth by the Brundtland Commission, the precursor to this new global emphasis in environmental debates was the 'discovery' of the 'ozone hole' (actually a selective thinning of the stratospheric ozone layer) and its linking to anthropocentric emissions principally in the form of chlorofluorocarbons (CFCs). The political impact of the scientific evidence was considerably enhanced by the ability to graphically represent the 'hole' through the use of colour-enhanced satellite imaging and by the links to health effects, in terms of malignant melanomas (i.e. skin cancers) from exposure to sunlight for light-skinned peoples in geographical zones beneath the thinning ozone layer. Colour pictures and a cancer scare made for considerable media coverage. The problem of anthropogenic ozone thinning was tackled by international agreement for collective action through the Montreal Protocol adopted in 1987, assisted by the possibility of a technological substitute for CFCs and the willingness of the key economic actor DuPont, as producer of the substitute chemicals, to support the agreement (Rowlands, 1995).

However, the whole 'ozone hole' episode was important in establishing the possibility of global environmental change through anthropogenic causes and the need for collective action at the global scale to tackle such change. In this context, scientific communities began to make new claims for evidence of global climate change. Again there were anthropogenic sources, in this case the so-called 'greenhouse gases', mainly carbon dioxide and methane. The principal blame for such emissions was laid at the door of the fossil fuel economy, since the burning of coal and oil was the key source of carbon dioxide. NGOs, the media and some policy-makers began to talk of and write about the 'greenhouse effect' as a way of popularizing the more complex scientific processes lying behind the thickening of layers of gases in the upper atmosphere that were reflecting solar radiation back to the Earth's surface.

There was considerable dispute over these scientific claims, dispute that continues to this day.
An Inter-Governmental Panel on Climate Change was convened in 1988 by the World Meteorological Organization and the UN Environment Programme to bring together the key scientists involved in research on this issue. It has produced a series of reports setting out the evidence for climate change and seeking to specify future scenarios with ever greater precision. Over time the IPCC has generated an 'almost-consensus' on the likely extent of climate change processes. However, it is in the nature of such forecasting exercises that precise figures cannot be given; rather ranges are offered as descriptions of the future. The current estimates of global averaged surface temperature increases lie within ranges of 1.4-5.8 degrees Celsius over 1990-2100. Such prediction of future ranges for climate change contrasts with the graphic pictures of ozone thinning that had already happened. The ranges themselves were also the subject of vigorous debate within the broader scientific community and, even as the scientific consensus has tightened, so a band of contrarian scientists has continued to present an alternative view of the future (McCright and Dunlap, 2003).

These debates on climate change set the context for the renaissance of the sustainable development concept. They suggested that human action was generating (and indeed had already generated) change in global environmental systems, which was going to have profound impacts on people across the globe. Among these impacts could be counted sea-level rise (estimated as a global mean sea-level rise of 0.09-0.88 metres over 1990-2100 but potentially rising as much as 6 metres if the Antarctic ice shelf fails), changed patterns of agriculture including the results of extended desertification, higher incidence of extreme weather events such as storms and heatwaves, changes in water availability, loss of habitats and species, and new public health risks.

Around climate change, a number of other issues with a global perspective were clustered in the 1980s and 1990s. The ecological consequences of deforestation, particularly of the tropical rainforest areas, in various parts of the world were highlighted by another set of scientific claims. Biodiversity was as frequently identified as a global environmental concern as climate change, and the anthropocentric implications of such biodiversity loss were highlighted in terms of potential medical treatments that awaited discovery within the gene pool. However, there were also broader concerns about the existence value of the rainforests and their intrinsic value, even their intrinsic right to exist. And linking these two global issues was the question of how to reduce the scale of deforestation. Logging was a particular cause of the reduction in scale and diversity of the rainforests and deforestation directly contributed to climate change by removing a carbon sink. In addition, loss of tree cover 
more generally was related to loss of soil fertility and increased vulnerability of agricultural land to erosion, with implications for food security.

This mix of global environmental concerns provided a distinctive context for the deliberations of the Brundtland Commission. They gathered evidence from a wide variety of sources, including both accredited experts and local communities across the world, in an innovative mix of site visits, deliberative meetings and public hearings (WCED, 1987: 359). It developed an analysis that framed the problem in terms of global inequalities in development, global environmental threats and potentially catastrophic global conflicts. This was presented in the Brundtland Report, Our Common Future, published in 1987. The report saw the solution to this problem as the pursuit of 'a new era of growth', but a very different kind of growth. This is the core of the definition of sustainable development - a form of growth that can reduce inequalities, reduce environmental threats and diffuse conflicts, all on a global scale.

The decades since the publication of the Brundtland Report have seen the sustainable development concept become embedded in policy statements at local, regional, national and international levels, although the public profile of the agenda has waxed and waned. After the publication of the report, an international summit on environment and development was convened in Rio in 1992. Two conventions (on biodiversity and climate change) were tabled alongside Agenda 21, a manifesto of the actions needed to achieve sustainable development. Afterwards the UN established a Commission on Sustainable Development to encourage national governments to draw up their own Agenda 21 and monitor their progress. Painfully slow progress was made in translating the Framework Convention on Climate Change into the Kyoto Protocol and agreeing to its implementation. It finally came into force in February 2005 but without the involvement of the USA, currently the world's largest carbon dioxide emitter.

In 2002 the UN convened a new summit, the World Summit on Sustainable Development in Johannesburg. This was intended to assess the progress that had been achieved in the twenty years since Rio. Little of real significance could be reported on any of the major themes of the Rio Summit: biodiversity loss, deforestation or climate change. However, the sustainable development agenda itself was moving on. In the intervening years, the UN Millennium Development Goals had thrown the emphasis onto issues of world poverty, child mortality, gender equality, education, food security and public health, although "ensuring environmental sustainability' was listed as one of the eight goals. So the focus during the WSSD was less purely environmental than had been the case at the Rio Summit. In more recent years, the coming into force of the Kyoto Protocol, together with continuing and increasingly dramatic scientific evidence of the more imminent impact of climate change, have somewhat redressed the balance. The meeting of the G-8 (the political leaders of the world's eight largest economies) in 2005 saw global poverty and climate change sharing the media headlines and policy agenda.

Sustainable development is therefore a core focus of policy debates, albeit a focus that is variably defined. So how can the concept of sustainable development be characterized if it is apparently so flexible? The next section explores this question.

\section{THE CONCEPT OF SUSTAINABLE DEVELOPMENT}

The definition of sustainable development that is most commonly cited is one taken from the Bruntland Report (WCED, 1987: 8): 'to ensure that [humanity] meets the needs of the present without compromising the ability of future generations to meet their own needs'.

This is a definition that is rooted in considerations of equity. The emphasis is on generations, viewed collectively, as being able to meet their needs, not their demands or their wants. In the context of global inequality this is a clear statement about priorities. Then there is also the emphasis on inter-generational equity. The concern here is that the forms of global environmental change discussed above are at least partly caused by current human activity, but that the major negative impacts of those changes will be borne by future generations, and to such an extent that their ability to meet their basic needs will be adversely affected.

In this formulation, current generations are effectively stealing from their collective children and grandchildren on a global scale. Current economic growth is achievable only because the negative inter-temporal externalities of that growth are being ignored. And that economic growth is underpinned by prevailing patterns of production and consumption so that the current generation's experience of these activities is intrinsically unsustainable. Examples of this include the reliance on fossil fuels for energy needs and as a raw material for production, the scale and growth of consumption levels and the rapid turnover in goods generating ever more waste, as well as demand for further production. While the underlying message of the concept is clear, the subtleties of this formulation can create problems for policy development and implementation. As a result there has been a search for simpler ways of defining sustainable development that still capture the combination of social, environmental and economic concerns wrapped up in the term. 
One common way to do this is to identify these different aspects as 'pillars' of sustainable development and then conceptualize their interrelationship. For example, they can be conceptualized as distinct but overlapping areas (see Figure 35.1). Potential development paths or policy approaches can then be mapped onto this Venn diagram model (Levett, 1998).

The idea here is that future possibilities should be judged against their contribution to each of the elements of sustainable development. Development that meets only economic criteria of viability and profitability would fall within the economic circle but outside any area of overlap. If there were also social benefits accruing from this development, then it would fall into the area of overlap between the economic and the social. If on the other hand there were environmental benefits, it would be the overlap between the economic and environmental areas that was relevant.

The goal of sustainable development is, therefore, to find development opportunities and future paths that fall within the centre of the Venn diagram where all three areas overlap. However, this would involve finding win-win-win development paths that offer benefits on all three fronts. In practice, this can be difficult and the emphasis is instead on identifying win-win options, focusing on two of the three pillars. For example, there is an approach that sees considerable potential for expanding the area of overlap between economic and environmental goals in Figure 35.1. This sees the hope of steering economic activity in more environmentally friendly paths. It looks at the historic trajectory of many developed countries, passing from a predominantly rural economy through a dirty phase of industrialization and then into a cleaner period of late industrialization and into a predominantly tertiary economy. From this trajectory the possibility of environmental impacts actually reducing with increased growth is seen as a historic reality and therefore a feasible future.

Under the banner of ecological modernization, these theorists see the potential of establishing a series of institutional incentives that would hasten movement towards a growth-oriented but environmental friendly society (Gouldson and Murphy, 1998). Such incentives would include a mix of fiscal arrangements, both taxes and subsidies, together with regulation. The aim would be a form of economic activity that was much more efficient in its resource use, increasing the output/resources ratio by a factor of 4 or even 10 (Weizsäcker et al., 1998). Waste would also be minimized as a corollary of this approach, reducing pollution and waste disposal problems. By including energy as a key resource, this approach would also tackle the spectre of global warming through reducing dependence on energy sources and simultaneously shifting from fossil fuels to renewable sources. The mixture of judicious governmental policy, technological innovations and continued reliance on market signals would realize sustainable development as a mix of economic and environmental goals within a predominantly unchanged economic system. However, the reliance on market signals to generate economic activity would not necessarily mean that social goals were satisfied; indeed, past experience suggests that such pursuit of economic

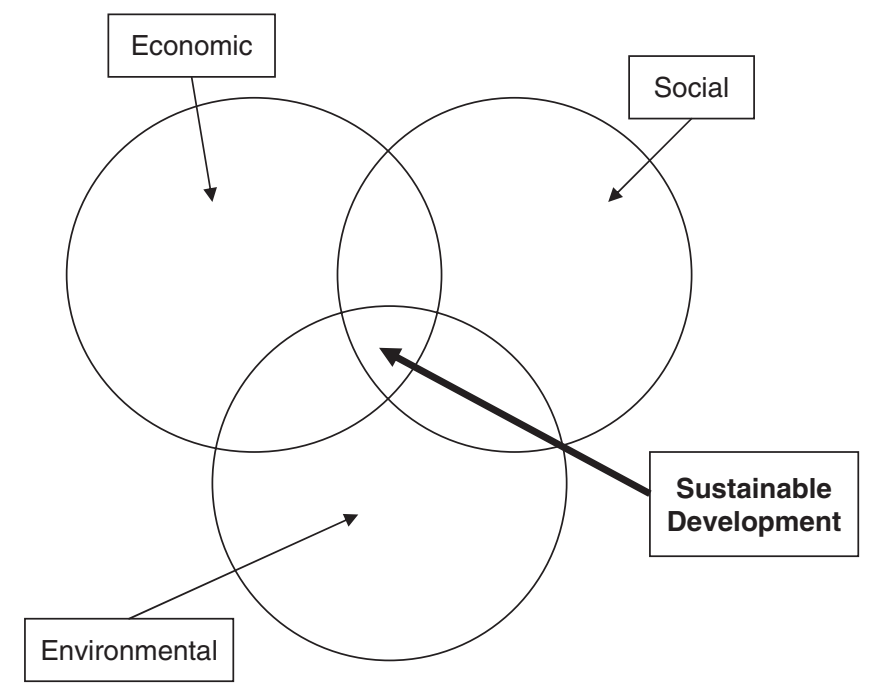

Figure 35.1 The Venn diagram model of sustainable development. 
growth may exacerbate social inequalities, at least in the short term. In a similar way, alternative paths can be identified that emphasize the possibility of finding synergies between environmental and social goals or economic and social goals under the banner of environmental justice (Agyeman et al., 2001) or corporate social responsibility (Zadek, 2001) respectively.

While the Venn diagram model suggests in its pictorial representation that all three elements are on a par, it is implicit in this model that economic processes are the appropriate starting point. For economic processes are seen as the route through which needs as well as demands are met, and are therefore inevitably at the core of sustainable development. This was a key assumption of the Brundtland Report, which called for a new era of growth as the way to tackle global poverty. While this growth is recast as development and not as a simple extension of conventional growth paths, this is still a future based on a variation of market-led or capitalist economic activity. This raises the question of how far current patterns of economic activity can be shaped to fit within a sustainable future (Jacobs, 1991). Some environmentalists have queried whether this provides a sufficient level of environmental protection or whether the pace of change might not be too slow to avoid ecological catastrophe. Instead they emphasize the critical nature of the environmental systems on which all other activities, including economic activity, must rely.

This is related to the distinction within sustainable development debates between weak and strong sustainability (Neumayer, 2003). In weak sustainability, the environment is seen as having valued dimensions for both its life-support functions and its abilities in providing food, other resources and the capacity of a pollution sink, but there are unlimited possibilities for compensating for environmental costs or losses through economic growth. Investment in other forms of physical and indeed human capital can be used to trade off environmental degradation. Thus, development in a rare ecological habitat can be compensated through creating other habitats or nature conservation features elsewhere. The use of environmental valuation techniques is often invoked as a way of enabling such trade-offs and compensation to be calculated and put into effect (Pearce et al., 1989).

However, critics of the weak sustainability position argue that some aspects of the environment cannot be substituted for or traded off in this way. Exactly which aspects fall into this category is debatable, but they may include climate control functions, pollution sinks with a limited capacity, valued landscapes, rare habitats, and areas of significant cultural heritage including historic buildings. These could all be termed critical natural capital (man-made capital in the case of historic buildings) and as such fall into a different conceptual category to other aspects of the environment that are not seen as so unique and important (Owens, 1994). The difficulty here is that the categorization of critical natural capital is inherently subjective, even where informed by scientific expertise that has widespread legitimacy. A site may be categorized as an ecologically important habitat, but this may differ from the value that society collectively places on such a habitat. Where landscape is concerned, many a NIMBY (Not In My Back Yard) campaign has been based around arguments of the uniqueness of an area and its views; this is not so much a question of whether the landscape should be classified as critical natural capital or not but rather whose view of what counts as critical natural capital is prioritized.

For some this problem arises because a range of cultural artefacts is being considered under the heading of critical natural capital when this term should properly be kept for the functioning of global environmental systems. The emphasis should thus be on global warming as a result of the overuse of global carbon sinks, losses in global (rather than local) biodiversity, and the inevitability of entropy reducing the ability to continually reprocess and recycle physical products through the application of energy sources. A focus on these aspects suggests a strong sustainability position in which not only are such environmental assets and services treated as non-substitutable, but a strong case is made for actual limits to economic growth. The promise of ecological modernization is seen as a false promise and instead measures are proposed to enable society to move towards a situation where it can live within the limits of 'Spaceship Earth'. Such measures can include Daly's (1992) draconian birth permits and resource quotas.

Such a strong sustainability perspective favours a Russian doll, as opposed to a Venn diagram, model of the concept (see Figure 35.2; see also Levett, 1998). Here the environmental concerns are seen as at the core of the concept, surrounded by social concerns, and only then economic concerns. The implication is that economic activity depends on social structures and, fundamentally, on environmental systems. Ensuring that economic development is sustainable means taking account of these environmental limits and the social constraints on routine economic decision-making and leads to demands for more radical changes in social organization and economic practices. This then raises the question of how contemporary routines of politics and policy can respond to such a radical agenda and, more broadly, the relationship between governance processes and sustainable development. 


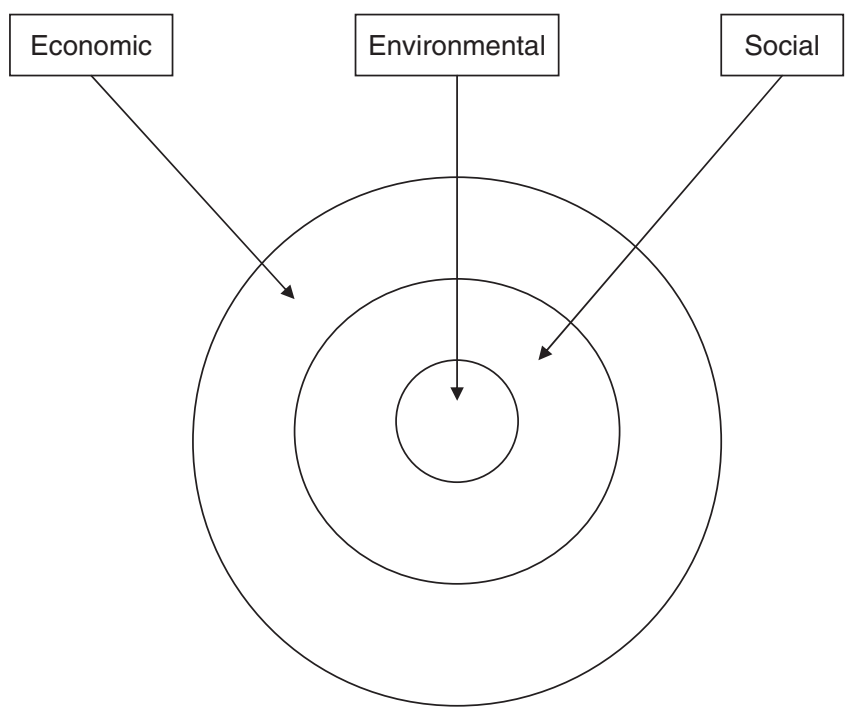

Figure 35.2 The Russian doll model of sustainable development.

\section{GOVERNANCE AND SUSTAINABLE DEVELOPMENT}

The pursuit of good governance is sometimes referred to as the fourth pillar of sustainable development, suggesting that sustainable development is also about new ways of doing policy as much as new outcomes. Why should governance be seen as so integral to sustainable development? To understand this, it is necessary to understand the concept of governance too (Rhodes, 1995).

Governance can be understood as a descriptive account of trends in contemporary society affecting the state and the public sector (although there is a parallel trend concerning the corporate sector see below). At the core of this trend is a different relationship to stakeholders; indeed it implies the identification of a broader range of actors as having a 'stake' in a policy issue. Over the last two decades there has been a shift within many countries and across many international organizations towards relying on stakeholder involvement not just for consultation during the formulation of policy, but in terms of a more meaningful involvement, participating in decision-making and even taking responsibility for the delivery of policy outcomes. This shift arose from the recognition during the late 1970s and 1980s that governments and their agents often did not have the 'capacity to act', to implement effectively and deliver on their policy intentions. Many of the key resources - financial but also informational and capacity building depended on the involvement of non-state actors. Involvement throughout the policy process could also avoid conflict at a later stage holding up policy delivery and could provide greater legitimacy for policy outcomes. For all these reasons, stakeholder involvement under conditions of governance became increasingly prevalent during the late twentieth and early twenty-first centuries.

Analytically this has thrown the emphasis on understanding how complex sets of networks interrelate within policy contexts. Such networks describe the interconnections between actors, allowing governance to be characterized in terms of the range and density of connections but also the identification of nodes that are particularly central within any policy process. Analysis can go beyond such description to understand the dynamics involved in networks by considering how resources are activated through the network links. This provides an insight into the power relations implied by governance processes. There is a split here between those who see power as an attribute of actors within governance networks, partly based on the resources they hold, and those who adopt a relational view of power, in which power is based on attributes of the network itself. In either case, though, the combination of network links and resource flows provides the basis for understanding governance processes.

New Institutionalists go beyond this to consider how networks are turned from sets of linkages into institutions with a long-term life (Hall and Taylor, 1996). This involves seeing how the behaviour of actors within networks becomes embedded over time creating path dependencies and thereby guiding outcomes. This is not a deterministic approach to understanding governance but rather one that seeks to combine a focus on actors' behaviour and 
decisions as well as the context within which they act. Actors remain invested with agency and yet, in general, tend to behave in predictable ways with implications for outcomes and distributive impacts on others. The role of cultural factors such as norms, values, customs and working routines (all discursively mediated; Rydin, 2003) are important in embedding behaviour and creating this context.

But governance has not just been used as a descriptive label or to define an analytic institutionalist framework. It has also been extensively used as a normative perspective. Governance is not only a response to identified problems in the public sector, but also a democratic ideal suggesting a way of empowering communities and other stakeholders within the policy process. And as a normative approach, governance has spread beyond a concern with governmental bodies and policy processes to arenas in the economy and civil society. Corporate governance describes new ways that are recommended for firms to engage with a variety of relevant stakeholders, from shareholders to customers to workers to local communities near sites of production. Just as governance is recommended as a better way to do policy and corporate governance is seen as a better way to do business, community governance has been taken up as a means of empowering local communities and ensuring that they are both effective and operate on the basis of inclusion. In all these arenas, governance is seen as a desired future.

A normative emphasis on governance was apparent within the process of developing the Brundtland Report itself, as mentioned above. The Brundtland Commission operated in an open and inclusive manner, visiting many local communities as well as national governments and taking evidence from a range of actors from scientific experts to local villagers. In its report it emphasized the importance of involving as wide a range of affected or interested parties as possible in building the consensus for a change of direction towards sustainable development. Stakeholder involvement has, therefore, come to be seen as emblematic of all sustainable development politics and policy-making. Beyond the totemic influence of the Brundtland process, there are other reasons why governance is particularly pertinent for proponents of sustainable development.

As a policy goal, the complexity and ambiguity of the concept of sustainable development puts particular pressures on the policy process. It requires considerable effort to specify how the concept is to be defined in specific contexts. The Brundtland definition may inspire but it needs further specification. The above discussion has highlighted that, in the absence of obvious and easy win-win-win options, there is a need to make difficult choices between environmental, economic and social concerns and alternative packages of outcomes. The very notion of constraining current generations for the benefit of future generations - which is at the core of sustainable development - also places strains on the legitimacy of policy systems, particularly those accustomed to delivering within the electoral time scale of a democratic government. Governance can be a way of trying to handle these pressures and strains.

Turning to implementation, sustainable development requires multiple sets of interventions in different domains in order to achieve the desired mix of environmental, economic and social outcomes. Networks bringing together actors in these different domains can help coordinate these interventions. It can also release resources from varied locations to support implementation. Conventional knowledge sources may well provide weak support given the emphasis on predicting future strains on environmental systems and the inherent uncertainties in such predictions. In such a situation there is a need to obtain buy-in to the scenarios of the future underpinning policy development. There may also be benefits in bringing together information and knowledge from a wide range of sources including local knowledge. For all these reasons, advocates of sustainable development have seen broad and open stakeholder involvement as the appropriate mode of policy work.

Beyond these policy-based rationales, there are also strong spatial reasons why governance processes are particularly appropriate to the pursuit of sustainable development. To understand this, it is necessary to unpack some of the spatial inequalities associated with the social and environmental impacts of economic development. These can be defined at five levels: site-level impacts, locality impacts, filière impacts, transport-related impacts and aggregate impacts (see Table 35.1).

Site-level impacts refer to the environmental effects of the differential distribution of economic activity (both in terms of total quantity and types of economic activity) across space. For example, there are the positive environmental consequences of land reclamation for development as opposed to the negative ones associated with deforestation or other primary resource exploitation, or with the abandonment of sites. Such variations in environmental impacts are linked closely to the social impacts, so that negative environmental impacts at this level often go alongside the limited or declining social benefits arising from economic development patterns. Such ties can be very difficult to break, whether they relate to vicious cycles of declining economic investment, increasing environmental degradation and social deprivation, or those associated with economic investment based on low-wage labour and poor environmental conditions.

Next, there are locality impacts, which go beyond the immediate site to consider the effects on the locality and its hinterland, often termed 
Table 35.1 Spatial aspects of sustainable development.

\begin{tabular}{|c|c|c|}
\hline & Spatial distribution of environmental impact & Socio-economic dimension \\
\hline Site impacts & $\begin{array}{l}\text { Differential distribution of economic activity and of } \\
\text { different types of economic activity create negative } \\
\text { or positive environmental impacts on site, e.g. } \\
\text { deforestation (cf. land reclamation) }\end{array}$ & $\begin{array}{l}\text { Connection between patterns of new } \\
\text { development and existing spatial } \\
\text { equalities; urban regeneration testifies } \\
\text { to difficulties of reversing vicious cycles } \\
\text { in the location of development; } \\
\text { clustering of different forms of economic } \\
\text { acitvity relevent here }\end{array}$ \\
\hline Locality impacts & $\begin{array}{l}\text { Pattern of local negative environmental externalities } \\
\text { are associated with development, e.g. traffic } \\
\text { generation, waste dumps }\end{array}$ & $\begin{array}{l}\text { Strongly connected with distribution of } \\
\text { social inequalities so that lower-income } \\
\text { and certain ethnic groups suffer } \\
\text { disproportionately from such negative } \\
\text { externalities; tied into environmental } \\
\text { justice debates }\end{array}$ \\
\hline $\begin{array}{l}\text { Linked impacts } \\
\text { over distance }\end{array}$ & $\begin{array}{l}\text { Filières of economic activity that connect places across } \\
\text { space to support production and consumption } \\
\text { patterns also connect differential environmental } \\
\text { impacts, e.g. food consumption in North and food } \\
\text { production in South }\end{array}$ & $\begin{array}{l}\text { Raises issues of how development across } \\
\text { space is organized and the importance } \\
\text { of spatial distancing of environmental } \\
\text { impacts in creating econemically viable } \\
\text { development; connects to the spacial } \\
\text { distancing of different social groups also }\end{array}$ \\
\hline $\begin{array}{l}\text { Impacts of } \\
\text { transport over } \\
\text { distance }\end{array}$ & $\begin{array}{l}\text { The transport dimension of such economic filières } \\
\text { generates non-local environmental impacts; at a } \\
\text { regional scale through migratory pollution and at a } \\
\text { global scale through global warming }\end{array}$ & $\begin{array}{l}\text { The spatially distanced nature of economic } \\
\text { and social activity is a major cause of } \\
\text { non-local and aggregate environmental } \\
\text { impacts through transport }\end{array}$ \\
\hline Aggregate impacts & $\begin{array}{l}\text { Where the patterns of consumption and production in } \\
\text { aggregate create environmental impacts, these are } \\
\text { then distributed unevenly across space; global } \\
\text { warming is a key example with its spatially } \\
\text { differentiated impacts, say in Scotland and England }\end{array}$ & $\begin{array}{l}\text { The socio-economic dimension is linked not } \\
\text { to the physical effect but the } \\
\text { vlunerability, the ability to cope with } \\
\text { change, e.g. Florida and Bangladesh }\end{array}$ \\
\hline
\end{tabular}

spatial externalities. Different kinds of economic development give rise to different patterns of local negative and positive environmental externalities. For example, there are the negative externalities associated with development in the form of pollution from traffic generation, noxious industry or waste facilities. Much environmental and urban planning activity aims to manage the spatial pattern of such externalities. The environmental justice movement has shown how, despite or perhaps even because of such planning, the pattern of negative environmental externalities is closely related to the spatial distribution of classes and ethnic minorities. Empirical evidence has repeatedly demonstrated the strong connection between the location of environmental 'bads' and the residency of lower-income groups and communities of colour, so that lower income and certain ethnic groups suffer disproportionately from negative environmental externalities (Agyeman et al., 2001).

These two kinds of impact depend on the spatial proximity of certain economic activity and the associated environmental and social impact. The next category refers to impacts linked over distance between different places. This draws on the notion of filières of economic activity that connect places across space (Amin and Thrift, 1994). Such connections are necessary to support production and consumption patterns so that economic processes in one location depend on parallel processes in other locations. These filières also connect environmental impacts in different locations across space. For example, food consumption in developed countries is dependent on the production of such food in less developed countries, whether it is mange-tout peas from Africa or beef fed on soya from South America. There is therefore a link between the environmental impacts of such pea and soya production and the sites of consumption, even though they are spatially distanced. The notion of food chains, linked to the broader concept of global product chains, tries to capture these trans-spatial links. This raises important issues of how development across space is organized and the potential significance of the spatial distancing of environmental impacts from consumption sites in creating economically viable development. This builds on a long-established political economy argument about the reliance of capitalist profit-making on the spatial distancing of different social groups (Massey et al., 1984). 
Spatial distancing of production and consumption activities (including intermediate production) further results in the impacts of transport over distance. The environmental impacts of transport are well known. They generate pollution at the local level in terms of poor air quality, at the regional scale through migratory pollutants such as sulphur oxides and ozone, and at the global scale through global warming. The longer the economic filières, the greater are the environmental transport effects. Thus there is a strong connection between the environmental and social impacts of linked economic activities over space and the impacts of transport over that same space. One aspect that has received particular attention has been the distance travelled by food consumed, conceptualized as food-miles. One of the major components of analyses of ecological footprints - which seek to draw attention to the environmental impact of cities' and countries' consumption patterns - is the food-miles embodied in collective shopping baskets (Chambers et al., 2000).

Finally, in terms of spatial aspects of sustainable development, there is the distribution of aggregate environmental impacts. This particularly relates to the impact of global warming arising from the aggregation of myriad local decisions about energy use (and, in terms of methane generation, activities such as waste disposal and animal husbandry). The environmental impacts of global warming are and will be distributed unevenly across space. This is a largely physical phenomenon as sea-level rise impacts differently in, say, the north and south of England due to the height of land above sea level and the ongoing tilting of the landmass of the British Isles. However, the social and economic consequences of such environmental impacts are due to the vulnerability of societies and communities and this, in turn, relates to the level of economic development and associated wealth, and the capacity of political systems. Such vulnerability refers to the ability to cope with change, both incremental and catastrophic change. So the differential impact of global warming on Florida and Bangladesh relates not so much to their different physical characteristics but rather the ability of the public and private institutions to manage flooding, coastal erosion and more frequent periodicity of storms.

So, returning to the issue of how governance handles these spatial aspects, it is helpful to examine how the networks of governance handle spatiality. Policy networks focused around sustainable development involve multiple stakeholders and perspectives on the sustainable development concept. They also have to confront the uneven environmental and social impacts of economic development across space. This requires governance processes that are not simply based in one locality or territory. Rather they need institutions that can handle such impacts over space, negotiating between territorially based organizations to achieve trade-offs or win-win options and enabling collective action at levels above such territorial bodies in the face of the threat of free-riding. And yet existing organizations operate from specific locations, have defined territories and/or are identified with particular scales. Governance seeks to operate across these organizational limitations to link place, territory and governmental tier. In these ways they hope to manage the spatial dimensions of the sustainable development concept.

The development of multi-level governance (MLG) in sustainable development policy is a prime example of how institutional arrangements have developed to try and deal with such fragmentation. In particular, MLG has evolved to ensure that the networks concerned with sustainable development in any one locality or at any one scale have to deal with networks at higher and lower levels. Peters and Pierre (2001) define MLG in terms of the vertical layering of governance at different levels, so that local, regional, national and supranational governmental or quasigovernmental bodies are all involved in policy. The existence of all these layers results in complicated and overlapping networks for any specific policy domain such as sustainable development But, in addition, Peters and Pierre point to the potential within MLG for organizations within one tier to bypass the immediately superior or ulterior tier and relate directly to bodies in a different and more distant tier. Thus, local municipalities within Europe deal directly with the European Union on some issues (including many urban sustainability initiatives) rather than going through the national governments.

The rationale for MLG is seen by Peters and Pierre to reside in the weakening of the national state by fiscal crises in the later twentieth century, the rising challenge of emerging transnational bodies such as the European Union, the tendency towards decentralization within national governmental systems even if only on an informal basis, and the rise of New Public Management approaches to public administration that favour guidance and steering over direction by governmental bodies. A useful example of the different forms that the imperative towards MLG can take is provided by Kern and Löffelsend (2004) in their study of the Baltic Sea region. Here they identify three different types of MLG institution. There is international governance by nation-states, which can further take the form of international regimes (such as the Helsinki Convention) or intergovernmental cooperation (as with the Council of Baltic Sea States). Then there is international governance with nation-states but also involving other kinds of stakeholders; the example they give is Baltic 21, the Agenda 21 for the Baltic Region, which is a form 
of international policy network. Finally, there is transnational governance without nation-states as in transnational networks, for example, the Union of Baltic Cities.

These complex organizational arrangements across tiers of government are an attempt to deal with the trans-spatial nature of environmental impacts and of sustainable development. However, the emergence of such arrangements has not been without its problems. Lundqvist (2004) has pointed to the 'trilemma' of policy that MLG seeks to tackle, that is, the mutual attainment of policy efficiency, participation and legitimacy. Examining the case of water management, he contrasts the efforts to achieve ecological efficiency through catchment area-based planning, while also involving a wide range of stakeholders and achieving a legitimate outcome backed by accountable decision-making (traditionally the preserve of elected governmental bodies). He sees these tensions as inevitable within MLG, unresolved by the attempt to create more and more network institutions.

To give a further example: as government actors have extended policy processes to involve those outside the governmental sectors in order to achieve better policy delivery and legitimacy, the very complexity of networks themselves can threaten the ability to deliver and can obscure lines of accountability. Governments have often sought to maintain a degree of control through steering mechanisms such as indicators or targets, often linking achievement as measured by these means to the release of financial resources; this is at the heart of New Public Management. However, a governmental body that is looking towards better performance according to given measures can often be frustrated by the uncertainties of more open stakeholder involvement and, as a result, may seek to limit that involvement. In this way, tensions are built into the governance processes of sustainable development policy.

While MLG is one important form that governance for sustainable development has taken, specifically local governance has also been given considerable emphasis within sustainable development policy. The final section explores local governance to show exactly how governance can promote sustainable development in practice.

\section{EXAMINING HOW GOVERNANCE CAN PROMOTE SUSTAINABLE DEVELOPMENT: THE CASE OF LOCAL GOVERNANCE}

The rationale for local governance for sustainable development mixes instrumental and democratic imperatives, as is typical of all governance arguments. On the one hand, it can be argued that it is at the local level that there is the greatest scope for actors to become involved in the policy process. At higher scales or tiers there are likely to be barriers to involvement with representatives of groups, sectors or communities favoured over the individual citizen; at the local level the individual citizen may participate directly without the need for a representative acting on his or her behalf, (although this point can be overstated since representation may be inevitable even at local levels). More practically, it is argued that participation by larger numbers of actors is more likely to be successful at the local level. On the other hand, instrumental reasons for participatory governance are that implementation of sustainable development policies will be facilitated. For example, awareness-raising will be more effective at the local level and this will in turn spur on the behavioural changes that are needed for more sustainable consumption and production patterns. Furthermore, local networks embedded through governance processes may directly generate sustainable patterns, particularly where there is direct local engagement with natural resources.

\section{Local Agenda 21}

The above rationale lies at the heart of the Local Agenda 21 (LA21) movement. LA21 has its origins in Chapter 28 of Agenda 21 (which, as discussed above, was tabled at the 1992 Rio Summit), setting out the importance of local communities in actually delivering sustainable development (Lafferty, 2001). However sustainable development is defined, it can ultimately only be delivered by changes in the behaviour, decisions and actions of households, firms, NGOs, governmental and quasi-governmental bodies at the local level. Therefore each locality should have its own Agenda 21. In the early days of LA21 the emphasis was on the process involved, with a concerted attempt by proponents of the LA21 movement to create a new form of local policy process. Consensus-building, visioning and awarenessraising were given central place, with considerable effort going into a variety of events to bring sustainable development to the notice of the local community at large. Schools were often targeted as a way of reaching local households. Events were designed to be enjoyable rather than just educational and the energies of local environmental NGOs were harnessed to create an atmosphere of local activism.

Some localities took a more structured approach with sectoral workshops being set up to examine particular topics and issues. These workshops could focus on the key stakeholders, so that, for example, the transport working group could bring together public transport providers, the police, 
traffic management within the local authority, planners, cycling organizations and consumers' groups. But there was almost universal agreement that the broader public needed to be engaged too. The exact form that this public involvement took depended on the role that local government adopted. In some localities - principally municipalities in developed countries with a strong tradition in local environmental management - the process could tend towards consultation. At the other end of the spectrum, though - principally in localities where the local authority had little legitimacy or record of efficacy - local communities sometimes took control of the LA21 process and used it as a means of community empowerment, demanding involvement in and even control over new areas of local policy. And along the spectrum were attempts by local authorities to engage with their communities in a more meaningful way to deliver sustainable development (LASALA, 2001).

To explain how LA21 can be effective, the nature of network relationships within governance requires a little more explanation and, in particular, the focus needs to turn to the situation of actors within networks. Networks have been introduced as sets of relationships between actors, operationalizing resources and embedded in norms and routines. Actors find themselves at the intersection of resource flows from multiple directions. Their behaviour and decision-making will be a response to the impact of these resources on their position, their interests and values in the context of the cultural aspects captured by norms, values, routines, and so on. The term 'incentive structure' describes the set of factors that shape such behaviour and decisions from the actor's perspective. It is important to emphasize that, tied up in the idea of an incentive structure, are material resources, power and interests but also the range of cultural attributes.

Such an analysis of governance can be very helpful in explaining how governance works in specific circumstances and, in particular, the level of participation that is achieved. From this perspective, participation is a result of actors weighing up the costs and benefits of participating in a particular institutional context. The costs will include the time, effort and monetary expenditure involved in participation; all these costs are likely to be certain, impacting in the present day and falling directly on the actors that decide to participate. The benefits will include the likely outcomes of the collective participation effort; these are likely to be uncertain, arising in the future and to benefit a larger, possibly ill-defined group. The temptation to free-ride rather than be actively involved in the governance effort will be considerable. Such an explanation defines the collective action problem that constrains participation and hence the success of governance processes.
This explanation also offers insights into how to overcome the collective action problem and enable participation (Rydin and Pennington, 2000). Successful strategies would focus on reducing perceived costs and raising perceived benefits; for example, paying childcare costs, setting events at the most convenient time for participants, making events more enjoyable, publicizing the likely benefits to arise from participation, and focusing on issues with an immediate benefit to participants (at least in the beginning). From this partial list it can be seen that encouraging involvement in governance for sustainable development faces particular problems since many of the benefits are likely to favour future generations and spatially distant communities. It takes a very strong value base among participants to discount the costs relative to the benefits and overcome the collective action problem in such instances. Proponents of sustainable development have argued that it is best to start from more local concerns (such as the quality of local green spaces for recreation and nature conservation) and then move outwards to more global and trans-spatial concerns (such as global biodiversity). They place their faith in the possibility of transforming the local to the global.

For example, the environmental justice movement has been criticized for being based in NIMBY (Not In My Back Yard) politics, in that the affected communities are essentially concerned to remove locally unwanted land uses - in another acronym, known as LULUs - such as toxic waste sites from their locality. They have not traditionally been concerned with where these LULUs might go. However, environmental justice activities have more recently sought to use debates about the local location of such facilities to raise the more general question of how contemporary economic production generates waste and to argue for more sustainable modes of production rather than just shifting the location of waste sites (Harvey, 1996). A similar transition occurred in nuclear planning in the UK in the twentieth century where local communities supported by environmental groups used debates about the planning of nuclear installations to raise questions (often against the wishes of central government) about the need for nuclear power at all and the links to the nuclear arms race. Such a transition from the local to the global is not guaranteed, however, and there remains the important first stage of enabling collective action within the local community first.

One way of encouraging collective action that has received considerable attention has been the generation and embedding of social capital. Social capital as a descriptive term suggests a specific kind of network, one with dense relationships, characterized by recognition of the mutual interest between actors and reciprocity in their dealings 
with each other. Pretty and Ward (2001) refer to four aspects of social capital: relationships of trust, which enable cooperation and reduce transactions costs between actors; reciprocity and regular exchanges between actors; common rules, norms and sanctions; and connectedness between actors through groups and networks. As a normative term, social capital theorists argue that creating such dense, mutual and reciprocal networks can overcome collective action problems. The key to this lies in the way that norms and values can be built into networks through repeated interactions between actors, so as to alter the incentives facing individual actors within the network. Establishing norms of mutuality and reciprocity means that actors who engage in collective action develop a positive reputation while those who free-ride will suffer the soft sanctions of loss of reputation and be 'shamed and blamed'. These cultural aspects of networks can be very effective in preventing freeriding. In addition, such institutions can develop norms for handling conflict and instances of freeriding through monitoring and enforcement by the network itself rather than an outside agency, thereby maintaining high levels of collective action.

\section{COLLECTIVE ACTION FOR SUSTAINABLE RESOURCE MANAGEMENT}

In addition to its role in enabling collective action in terms of stakeholder participation in sustainable development politics and policy, Ostrom (1990, 1992) has argued that social capital can enable direct community management of local resources in a way that contributes to sustainable development. For example, she has proposed developing local institutions for water management based on social capital. She has particularly emphasized how collective action can be developed in smaller and more homogeneous communities in a way that enables robust and sustainable management of resources. This argument is based on the quasipublic-good characteristics of many environmental assets and services, whereby individual actors exploiting the resource in their own interest collectively result in the degradation of the environmental asset or service. Collective action to prevent such collective degradation is subject to free-riding, in that each individual actor sees it as in their interests to continue to use the environment rather than collectively manage this exploitation; a free-rider reason in that 'others can regulate their use but I will benefit from continuing to use it as before'. Proponents of social capital, however, argue that building up social capital prevents this collective action problem and enables collective sustainable management of the environment, particularly through the opportunities enhanced by social capital for monitoring and the use of soft sanctions.

Social capital theory thus suggests that building new institutional arrangements about networks specifically oriented towards mutuality, reciprocity and trust can be an effective way of overcoming collective action both in terms of sustainable natural resource management for local communities dependent on such resources and in terms of involving a broader range of actors more effectively in general policy efforts for sustainable development. The key to success here is creating new incentive structures for actors involved in such networks. These will be shaped by the detailed design of the institutions, the precise extent of the networks and the way that working routines for the network embody certain values and norms. Recently, social capital theory has emphasized the different kinds of social capital that may be used in such institutional design.

Most emphasis has traditionally been placed on bonding social capital, which is used to create strong ties between a delimited set of actors. Where such actors form a homogeneous and relatively small group, then experience suggests that bonding capital can be most easily fostered. However, this can be at a cost. Strong ties between members of the group may reduce the possibility of links with actors outside the group. This can be useful where the management of a local resource - say, a village watercourse or grazing ground - is at issue, but less useful when dealing with complex goals such as sustainable development where links between a variety of stakeholders of different kinds and not all with local stakes will be needed. There is also the potential for strong bonding capital to have a 'dark side' through cementing institutional arrangements that effectively terrorize local communities, as in Mafia or terrorist organizations.

Hence, there has been the suggestion that an alternative form of social capital, known as bridging capital, may be needed. Bridging capital is also known as weak ties and is used to bring unlike actors together, from different communities or groups. Many researchers have seen bridging capital as a useful complement to bonding capital. For example, it may be used to tie in NGOs organized on a non-local scale with local communities. However, bridging capital is very weakly conceptualized and can amount to little more than a network linkage out from a group or community. Usually no limits are placed on the extent of bridging capital and no explanation provided of how its efficacy is affected by the length or character of the linkage. These limitations of the bridging capital concept have led to the suggestion that a third type of social capital is often needed, particularly in stakeholder engagement of the type found in strategic planning for sustainable development (Rydin and Holman, 2004). 
This third type is called bracing capital and it describes the kind of linkages found in policy contexts where a limited set of varied actors need to be bound together in collective action. Such actors form a delimited set and therefore unlimited bridging is inappropriate. They are a differentiated group so that bonding on its own will not be effective. What is needed in a mix of strong and weak ties within this delimited and differentiated set of actors in order to bring about collective action, in terms of agreement on working routines, specific policy outputs such as strategy documents and eventually common norms and values on policy direction. Careful institutional design is needed to create this type of bracing capital, but it holds the potential for underpinning collective action towards sustainable development.

That said, the emphasis on building institutions based on social capital as the favoured form of local governance for sustainable development is not without its limitations. There is always the danger that practice will fall short of the ideals of institution-building and tend instead towards routine consultation. In such circumstances the perceived need to build a consensus can lead to a 'rush to the bottom', with the lowest common denominator of agreement between actors being used to generate a weak and rather meaningless consensus. If strong local governance institutions are generated, they may be subverted to ends other than sustainable development and the ambiguities in the sustainable development concept used to disguise this. Thus, urban growth coalitions can adopt the language of ecological modernization to present themselves as promoting sustainable development, when the emphasis is much more on a continuation of past policy trends towards urban boosterism than on any breakpoint towards sustainable development. Then there is the considerable effort, including resources, required to create such institutions and, furthermore, to maintain them. More complex forms of networks based on social capital may not actually reduce transactions costs but actually increase them, reducing policy efficacy. And finally, it may not be the case that all sustainable development problems can be most effectively tackled through local institutionbuilding in this way, based on the involvement of communities and stakeholders (Rydin and Falleth, 2005).

There is an argument to be made that in some cases state direction, more reminiscent of government than governance, is a more effective way to change currently entrenched patterns of unsustainable consumption and production (Rydin and Pennington, 2000). Sometimes the collective action problem is just too considerable and the urgency of the policy goal is just too great to make it sensible to persist in governance efforts. States have implicitly continued to recognize this in their ongoing promotion of regulation as a basis for environmental and social protection. The benefits of using this approach sometimes should not be forgotten in the contemporary and often overwhelming emphasis on governance.

\section{CONCLUSION}

One of the strengths but also key weaknesses in the sustainable development concept is the way that it seeks to combine very different goals within one holistic package. This is bound to lead to alternative definitions of what sustainable development comprises when considered in detail and consequent ambiguity and confusion within policy processes. The open involvement of many different actors within structures of governance provides the opportunity for each actor to press for a definition that accords more closely with their interests and values. The concern of those seeking a greater emphasis on environmental protection or social equity is that inclusive governance processes may therefore result in 'business as usual' or a dilution of the radical potential of the concept.

Opening up sustainable development policy and politics to governance structures does not resolve the tensions between these different views of the concept. Governance merely provides an opportunity for different views to engage with each other and the outcome need not be a pluralist consensus or even compromise. Each governance process carries with it certain institutional characteristics including prevailing norms and values. These may be conducive to a more radical interpretation of sustainable development and associated social change, but there are good reasons to expect that governance institutions will be imbued with norms that constrain such interpretations and favour an emphasis on marginal change to existing patterns of social and economic behaviour. The institutionalist approach emphasizes the likelihood of actors following established patterns of behaviour under the influence of a prevailing 'logic of appropriateness' that constrains actors to behaving in ways already considered appropriate within that institution. Changing institutional logics and establishing new norms is like altering course with an oil tanker, a slow process. Opening up structures to the influence of multiple stakeholders will, in the initial stages, result in these stakeholders engaging with each other in the context of established norms, and this may favour policy options such as ecological modernization rather than more radical deep green alternatives. The result may be future outcomes that prove to be unsustainable as environmental assets are substituted or traded off in pursuit of economic and social gains. This debate continues most vividly around the 
implementation of the Kyoto Protocol in terms of just how much constraint on economic growth is justified to tackle greenhouse gas emissions. Governance offers no easy resolution of these debates.

At root, sustainable development requires a political, ideological and values-based shift, which new institutional arrangements may help to consolidate but cannot substitute for. Without such a shift, policy institutions will tend back to mere incremental change or even relapse to a 'business as usual' scenario. Moving beyond this will require an iterative process of value shift. Of course, if everyone agreed that a particular form of sustainable development was desirable, then policy actors would just be left with problem of implementation. The challenge is that there are contested views over what sustainable development is, how important it is, and how desirable any particular form is. Fundamentally, governance for sustainable development has to engage with these different views and with the underlying ideological debates.

The power of prevailing social ideologies is considerable, as cultural theorists, social constructivists and Foucauldians have long told us. Sustainable development is clearly not an embedded social ideology, despite its emblematic use in many policy contexts. Value shift will require a discursive challenge to prevailing ideologies or discourses. Some of this challenge will occur in the detail of developing institutions, specific networks and ways of working among actors. But there is also a broader canvas on which the battle for sustainable development has to be waged. This involves the interaction, through everyday communication between actors, of different discourses about how social, economic and political lives should be organized and how they engage with the environment. (Rydin, 2003) Any consideration of the future for sustainable development policy and politics will need to take on board that the development of governance processes must be part of a broader politics arguing the need for change.

\section{REFERENCES}

Agyeman, J., Bullard, R. and Evans, B. (2001) Just Sustainabilities: Development in an Unequal World. London: Earthscan.

Amin, A. and Thrift, N. (eds) (1994) Globalization, Institutions and Regional Development in Europe. Oxford: Oxford University Press.

Chambers, N., Simmons, C. and Wackernagel, M. (2000) Sharing Nature's Interest: Using Ecological Footprints as an Indicator of Sustainability. London: Earthscan.

Daly, H. (1992) Steady-State Economics. London: Earthscan.

Gouldson, A. and Murphy, J. (1998) Regulatory Realities. London: Earthscan.
Hall, P. and Taylor, R. (1996) 'Political science and the three new institutionalisms', Political Studies, XLIV: 936-57.

Harvey, D. (1996) Justice, Nature and the Geography of Difference. Oxford: Blackwell.

Independent Commission on International Development Issues (ICIDI) (1980) North-South: A Programme for Survival. London: Pan Books.

International Union for the Conservation of Nature (IUCN) (1980) World Conservation Strategy. Gland, Switzerland: IUCN.

Jacobs, J. (1991) The Green Economy. London: Pluto Press.

Kern, K. and Löffelsend, T. (2004) 'Sustainable development in the Baltic Sea region. Governance beyond the nation state', Local Environment, 9(5): 451-68.

Lafferty, W. (2001) Sustainable Communities in Europe. London: Earthscan.

LASALA Project Team (2001) Accelerating Local Sustainability Evaluating European Local Agenda 21 Processes, Vol. 1. Freiburg, Germany: ICLEI.

Levett, R. (1998) 'Sustainability indicators: integrating quality of life and environmental protection', Journal of the Royal Statistical Society, 161(3): 291-302.

Lundqvist, L. (2004) 'Integrating Swedish water resource management: a multi-level governance trilemma', Local Environment, 9(5): 413-24.

Massey, D. and Allen, J. with Anderson, J. (1984) Geography Matters! Cambridge: Cambridge University Press with the Open University.

McCright, A. and Dunlap, R. (2003) 'Defeating Kyoto: the Conservative movement's impact on US climate change policy', Social Problems, 50(3): 348-73.

Neumayer, E. (2003) Weak Versus Strong Sustainability: Exploring the Limits of Two Opposing Paradigms (2nd edn). Cheltenham: Edward Elgar.

Ostrom, E. (1990) Governing the Commons: The Evolution of Institutions for Collective Action. Cambridge: Cambridge University Press.

Ostrom, E. (1992) Crafting Institutions for Self-Governing Irrigation Systems. San Francisco: ICS Press.

Owens, S. (1994) 'Land, limits and sustainability: a conceptual framework and some dilemmas for the planning system', Transactions of the Institute of British Geographers, 19(4): 439-56.

Pearce, D., Markandya, A. and Barbier, E. (1989) Blueprint for a Green Economy. London: Earthscan.

Peters, B.G. and Pierre, J. (2001) 'Developments in intergovernmental relations: towards multi-level governance', Policy and Politics, 29(2): 131-35.

Pretty, J. and Ward, H. (2001) 'Social capital and the environment', World Development, 29(2): 209-27.

Rhodes, R. (1995) 'The New Governance: Governing Without Government', Swindon: ESRC.

Rowlands, I. (1995) The Politics of Global Atmospheric Change. Manchester: Manchester University Press.

Rydin, Y. (2003) Conflict, Consensus and Rationality in Environmental Planning: An Institutional Discourse Approach. Oxford: Oxford University Press.

Rydin, Y. and Falleth, E. (eds) (2005) Networks and Institutions for Natural Resource Management. Cheltenham: Edward Elgar. 
Rydin, Y. and Holman, N. (2004) 'Re-evaluating the contribution of social capital in achieving sustainable development', Local Environment, 9(2): 117-34.

Rydin, Y. and Pennington, M. (2000) 'Public participation and local environmental planning: the collective action problem and the potential of social capital', Local Environment, 5(2): 153-69.
Weizsäcker, E., Lovins, A. and Lovins, L. (1998) Factor Four: Doubling Wealth, Halving Resource Use. London: Earthscan.

World Commission on Environment and Development (WCED) (1987) Our Common Future. Oxford: Oxford University Press. Zadek, S. (2001) The Civil Corporation: The New Economy of Corporate Citizenship. London: Earthscan. 
